\title{
Discussion on Design Method of Prestressed Concrete Frame Joints with Spread-Ended Beams
}

\author{
LIU Qing-wen ${ }^{\mathrm{a}}$, LI Wen-Xv' ${ }^{\mathrm{b}}$, XU Qing-yunn ${ }^{\mathrm{c}}$, LV Chao ${ }^{\mathrm{d}}$ \\ School of Civil Engineering and Architecture, Nanchang Hangkong University, \\ nanchang 330063, China

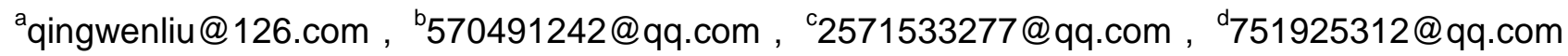

Keywords: prestressed concrete, frame joint, design method

Abstract. Based on the previous experimental and numerical analysis studies, the design menthod for prestressed concrete frame joints with spread-ended beams are proposed according to home and abroad related design codes and references, and the designed method is verified by test data. The results show that the method is feasible and can meet the needs of engineering. This method can be used in engineering design in engineering practice. Finally, the design measures for the beam-column joint core and the spread-ended region are recommended.

\section{Introduction}

In the seismic design of prestressed concrete structure, frame structure must have good ductility. In order to obtain better ductility, a large number of horizontal stirrups must be in the core area of frame joint. For prestressed concrete frame structure, overly dense stirrups will lead to difficulty in construction of prestressing tendons through the core area of joint. Adopting joints with spread-ended beams for the design scheme provides many advantages for construction. Reinforced concrete beam-column joint is a complicated and important member in frame structures, and takes a very important role in seismic resistance. Since the 1960s, numerous experimental and analytical studies have focused on the behavior of RC beam-column joint subjected to seismic loading and to establish guidelines for design ${ }^{[1-3]}$. However, most of studies have been conducted on the conventional joints. prestressed concrete joints with spread-ended beams, which are widely applied in buildings, are seldom reported in the literature. For joints with spread-ended, prestressing tendons do not take a direct action on the core area of joints because of anchorage and tendons embedded in the haunched. The potential advantages and applications of spread-ended beams is often ignored due to the lack of understanding in the performance of joints under seismic demand.

In this paper, based on home and abroad design codes and related reference literature, the design menthod for prestressed concrete frame joints with spread-ended beams are proposed according to my previous experimental and numerical analysis studies.

\section{Design method of joint}

\section{current concrete code in China}

In code for design of concrete structures (GB50010-2010) ${ }^{[4]}$ in china, the seismic shear capacity of frame joints is composed of two parts of concrete strut and horizontal stirrups. According to GB50010-2010, the shear bearing capacity of the beam column joints should be in accordance with the following provisions.

For 9 degree seismic precautionary intensity

$$
V_{j} \leq\left[0.9 \eta_{j} f_{t} b_{j} h_{j}+f_{y v} A_{s v j} \frac{h_{b 0}-a_{s}^{\prime}}{s}\right] / \gamma_{R E}
$$

For other conditions 


$$
V_{j} \leq\left[1 . \eta_{j} f_{t} b_{j} h_{j}+0.05 \eta_{j} N \frac{b_{j}}{b_{c}}+f_{y v} A_{s v j} \frac{h_{b 0}-a_{s}^{\prime}}{s}\right] / \gamma_{R E}
$$

Where $\gamma_{R E}$ is the adjustment coefficient of seismic capacity, $\eta_{j}$ is the influence coefficient of the constraint of the orthogonal beam, when concrete floors are cast-in-place, the beam-column center line is overlap, the width of four sides beam is not less than $1 / 2$ of the column width, and the height of the orthogonal direction is not less than the height of $3 / 4, \eta_{j}=1.5$. For 9 degree seismic precautionary intensity, $\eta_{j}=1.25$. when not meet the above constraints, $\eta_{j}=1.0 . f_{\mathrm{t}}$ is design value of tensile strength of concrete. $f_{\mathrm{yv}}$ is tensile strength of steel bars. $h_{j}$ is the cross section height of the joint core area. $b_{j}$ is the section effective width of the joint core area. $N$ is the axial force of the joints. $A_{s v j}$ is the cross-sectional area of stirrups in the core area of the effective width. $h_{b 0}$ is the effective height of the beam section, which can take the average value of the two sides of the beam.

\section{Other design methods in the literature}

R.park had done comparative prestressed concrete joint tests ${ }^{[5]}$. Study showed that a beam specimen didn't set up prestressing tendons, another specimen set up prestressing tendons in the middle of the beam, the beam size and flexural strength of two specimens were the same. Although both had the same stirrups in joint, obviously specimen with non-prestressing tendons destroyed much seriouser than prestressed specimen. In China, Southeast University professor Tang JiuRu also carried out research on prestressed concrete frame joints. According to the test results, referring to professor Tang JiuRu, Eq.(3) to calculate the shear strength of joints considering prestressing tendons ${ }^{[6]}$.

$$
V_{p}=0.4 N_{p}=0.4 \sigma_{p e} A_{p}
$$

Where $V_{p}$ is tendons contribution to the shear strength of joints, Respectively, $N_{p}$ is the force of joint core region by effective prestressing tendons, $\sigma_{p e}$ is the effective prestress, and $A_{p}$ is the area of the prestressing tendons through joint core region. For contribution of prestressed tendons to the shear capacity, the results show that the shear strength of joints should not take into account the contribution of prestressing tendons through joint outer region, otherwise overestimate the shear capacity of joint, therefore, $A_{p}$ is only the area of prestressing tendons through joint core region.

The stress of the concrete is restrained by the compressive stress of the prestressing tendon, and the shear strength of concrete is improved. According to the experimental data, the contribution of shear strength can be composed of concrete, prestressing tendon and stirrups and the expression is as follows:

$$
V_{j}^{c} \leq 0.1 \psi\left(1+\frac{N}{b_{c} h_{c} f_{c}}\right) f_{c} b_{j} h_{j}+f_{y} A_{s h} \frac{h_{0}-a_{s}^{\prime}}{s}+0.4 N_{p}
$$

\section{Shear design method of prestressed concrete frame joints with spread-ended beams}

According to the previous experimental and Numerical analysis studies ${ }^{[7-8]}$, We can know shear strength of concrete joint consists of three parts, namely shear capacity of concrete is $V_{c}$, shear capacity of reinforcement is $V_{s}$ and effect of prestressing force is $V_{p}$.

Shear capacity of concrete and stirrups is still in accordance with the current standard calculation formula. For the sake of safety, the beneficial effect of the addition of the axillary to the shear strength of joint is not considered when calculating the ultimate shear strength of joint.

$$
V_{c}=\left(1 . \eta_{j} f_{t} b_{j} h_{j}+0.05 \eta_{j} N \frac{b_{j}}{b_{c}}\right)
$$




$$
V_{s}=f_{y v} A_{s v j} \frac{h_{b 0}-a_{s}^{\prime}}{s}
$$

The contribution to the shear capacity of joints is known in the previous experiments and theoretical analysis. The effective prestress has little contribution to the improvement of the shear strength of the joints. The shear strength of the joints should be considered. Eq.(3) is used to calculate the shear strength of the beam column joints.

In summary, the shear strength of the prestressed concrete frame joints with spread-ended beams can be calculated by Eq.(7):

$$
V_{j} \leq \frac{1}{\gamma_{R E}}\left\{\left[1 . m_{j} f_{t} b_{j} h_{j}+0.05 \eta_{j} N \frac{b_{j}}{b_{c}}+f_{y v} A_{s v j} \frac{h_{b 0}-a_{s}^{\prime}}{s}\right]+0.4 N_{p}\right\}
$$

where $N_{p}$ is the effective prestressing force of tendons through joint core region.

\section{Comparison of experimental results and theoretical results}

In order to verify Eq.(7), it can be used to calculate the shear strength of the prestressed concrete frame joints with spread-ended beams. In this paper, we can take three specimens as example in the experimental studies $^{[8]}$. The model column length of $1650 \mathrm{~mm}$. The distance of the loading point on the beam end to the column section center is $1250 \mathrm{~mm}$. Column section size is $300 \mathrm{~mm} \times 300 \mathrm{~mm}$. Prestressed concrete beam section size is $200 \mathrm{~mm} \times 450 \mathrm{~mm}$. Concrete protection layer thickness is $25 \mathrm{~mm}$. The joint in the core area of the stirrup is $96 @ 60$. We can know the parameters of the specimens and material details from the literature [8]. According to Eq.(7) to check the joints shear capacity of three specimens.

The bearing capacity of the seismic adjustment coefficient $\gamma_{R E}$ is 1.0. $\eta_{j}=1, f_{t}=2.52 M P a$, $f_{y v}=393.9 \mathrm{MPa}, b_{j}=b_{c}=300 \mathrm{~mm}, h_{j}=300 \mathrm{~mm}, h_{b 0}=425 \mathrm{~mm}, a_{s}^{\prime}=25 \mathrm{~mm}, A_{s v j} / \mathrm{s}=1.88$ 。

We can know:

$$
\begin{aligned}
& V_{c}=\left(1 . \eta_{j} f_{t} b_{j} h_{j}+0.05 \eta_{j} N \frac{b_{j}}{b_{c}}\right)=261.48 \mathrm{kN} \\
& V_{s}=f_{y v} A_{s v j} \frac{h_{b 0}-a_{s}^{\prime}}{s}=296.21 \mathrm{kN}
\end{aligned}
$$

For specimens J1 :

$$
\begin{aligned}
& V_{j u}=V_{c}+V_{s}=261.48+296.21=557.69 \mathrm{kN} \\
& V_{j}=\frac{M_{b}}{h_{b 0}-\alpha_{s}^{\prime}}-V_{c o l}=\frac{V_{c o l} \times 1650}{(425-25)}-V_{c o l}=\frac{P \times 1250}{(425-25)}-\frac{1250}{1650} P=2.367 P
\end{aligned}
$$

When $V_{j}=V_{j u}$, we can educe ultimate capacity of $\mathrm{J} 1$ which is destroy under vertical loading $P=235.6 \mathrm{kN}$. The ultimate capacity of $\mathrm{J} 1$ in the experiment was $261.8 \mathrm{kN}$, more than $235.6 \mathrm{kN}$.

For specimens J3 :

$$
\begin{aligned}
& V_{j u}=V_{c}+V_{s}+0.4 N_{p}=261.48+296.21+0.4 \times 353 / 3=604.8 \mathrm{kN} \\
& V_{j}=\frac{M_{b}}{h_{b 0}-\alpha_{s}^{\prime}}-V_{c o l}=\frac{V_{c o l} \times 1650}{(425-25)}-V_{c o l}=\frac{P \times 1250}{(425-25)}-\frac{1250}{1650} P=2.367 P
\end{aligned}
$$

When $V_{j}=V_{j u}$, we can educe ultimate capacity of $\mathrm{J} 1$ which is destroy under vertical loading $P=255.5 \mathrm{kN}$. The ultimate capacity of $\mathrm{J} 1$ in the experiment was $273.6 \mathrm{kN}$, more than $255.5 \mathrm{kN}$. From stirrup strain curve derived from the experiment we can know when the beam reaches the yield load and stirrup strain of the joint core area also reached the yield ${ }^{[8]}$. 
In the same way, it can be verified that J5 also meet the requirements.Therefore, Eq.(7) and test results is in good agreement.

\section{Suggestions for construction measures}

In order to prevent the lateral collapse of the prestressed concrete spread-ended beam, the strength of concrete must be checked. Generally, the thickness of concrete protective layer is small, and the effect of concrete can not be considered for safety. The horizontal radial load should be assumed by the additional steel bars, and the area of additional bars should be set up. The cross-sectional area of single limb stirrups can be calculated as follows:

$$
A_{s v 1} \geq \frac{F_{l} s_{v}}{2 \times 1000 f_{y v}}
$$

Where $F_{l}$ is horizontal load, $A_{\mathrm{sv} 1}$ is section area of additional steel bars, $s_{v}$ is the distance of additional steel bars, and $f_{y v}$ is the tensile strength of additional steel bars.

In engineering application, the setting of additional $U$ shaped steel bars is mainly used in spread-ended region. The constructional detail is shown in fig.1. The anchorage length of $U$ bars should be calculated from the center of the channel, and the minimum anchorage length of steel bars should meet the requirements of the design codes for concrete structures.

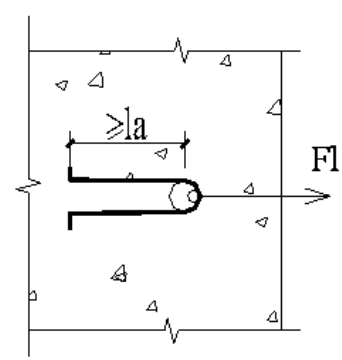

Fig.1 Constructional detail

\section{Conclusion}

1. The specific design method for prestressed concrete frame joints with spread-ended beams is proposed according to the author's previous result of experimental and numerical analysis studies. The designed method is feasible by comparison of experimental results and theoretical results.

2. The U shaped steel bars can be set up in the spread-ended region to prevent the lateral collapse of the prestressed concrete spread-ended beam, and the minimum anchorage length of $U$ shaped steel bars should meet the requirements of codes.

\section{Acknowledgements}

This work was financially supported by the National Natural Science Foundation of China(50968013), the Natural Science Foundation of Jiangxi (20114BAB206013), Jiangxi Education Commission Science Foundation (GJJ13510) and Graduate Innovation Fundation of Jiangxi Education Commission (YC2014-S405).

\section{References}

[1] Teeraphot Supaviriyakit, Amorn Pimanmas. Comparative performance of sub-standard interior reinforced concrete beam-column connection with various joint reinforcing details. Materials and Structures, Volume 41(3), p. 543-557.

[2] Aparup Biswal , A. Meher Prasad, Amlan K. Sengupta. Investigation of Shear Behaviour of Vertical Joints Between Precast Concrete Wall Panels. Advances in Structural Engineering, December 2014, p. 2323-2332.

[3] TANG Jiu-ru. Seismic design of reinforced concrete frame joints. Nanjing :South- east University Press, 1989. in Chinese

[4] GB50010-2010, Code for design of concrete structures. in Chinese

[5] R.Park,and K.J.Thompson,cylic Load Tests on Prestressed and Partially Prestressed Concrete Beam-Column Joints. Journal of PCI, 1977,Vol.22(5), p. 84-110. 
[6] TANG Jiu-Ru, PANG Tong-he, HUA Xia-ping. Experimental study on prestressed concrete frame joints Journal of Nanjing Institute of Technology,1988, 18(1), p. 14-22. in Chinese

[7] LIU Qing-wen, WU Fu-qiang. Finite-element analysis of prestressed concrete frame joints with spread-ended beams, advances in civil structures. Vols.638-640 (2014), p. 543-557

[8] LIU Qing-wen, WU Fu-qiang. Characteristic analysis of prestressed concrete frame joints with spread-ended beams, progress in industrial and civil engineering. Vols.578-579 (2014), p. 648-652 